\title{
Avaliação das disfunções do controle motor
}

\author{
Michelline Ribeiro Rodriguez, ${ }^{1}$ \\ Frederico Augusto R. Clemente ${ }^{2}$
}

\begin{abstract}
RESUMO - Os distúrbios do movimento compreendem o centro das atenções da fisioterapia. Este trabalho teve como meta principal o desenvolvimento de referencial que ofereça perspectivas atualizadas sobre a avaliação de pacientes com distúrbios da motricidade de forma a contemplar os aspectos fundamentais baseados no entendimento das principais interações neurais associados aos estágios de desenvolvimento e controle motor normal para que possamos planejar um tratamento baseado em fontes fidedignas, de modo a prever possíveis alterações e projetar metas mais realistas.
\end{abstract}

Palavras-chaves: distúrbios do desenvolvimento, controle motor, diagnóstico fisioterápico.

\section{Valuation of the motor control dysfunctions}

\begin{abstract}
Disturbance movements cover the center of attention into the physiotherapy. This paper develops and makes reference to the prospect up-todate about patient's valuation with motor disturbance. It contemplates all basic aspects of neurological patient's valuation based on neural interactions associated with its realization, as well as in the stages of development and normal motor control for to plan a treatment, based on real facts, to be able to predict possible alterations and to project realistic aims.
\end{abstract}

Key words: disturbances from the development, motor control, physiotherapist's diagnosis

\footnotetext{
${ }^{1}$ Fisioterapeuta, professora do UniCEUB e FARPLAC - mestra em Engenharia de Produção, especialista em Fisioterapia Neurológica. E-mail: michellineribeiro@yanhoo.com.br

${ }^{2}$ Fisioterapeuta, especialista em Fisioterapia Neurológica. E-mail: fred.ribeiro@ saude.al.gov.br
} 
O controle motor refere-se aos mecanismos responsáveis por produção e controle do movimento humano, um processo complexo que integra vários sistemas no organismo humano. Como não poderia ser diferente, a capacidade de analisar o movimento é pré-requisito essencial à avaliação de pacientes com deficiência do movimento (EDWARDS, 1995).

A avaliação em fisioterapia refere-se à coleta de informações necessárias para chegar-se a uma conclusão sobre o diagnóstico ou prognóstico de um paciente ou, ainda, para tomar decisões sobre a intervenção. Porém, as avaliações podem tornar-se rituais em vez de instrumentos valiosos, e a finalidade da avaliação da função física, que é registrar objetivamente, documentar e comunicar achados sobre distúrbios de movimento e os níveis de atividade pode não ser atingida (WADE, apud STOKES, 2000).

\section{O controle motor}

Segundo Smith (1997), controle motor designa a regulação da postura e do movimento, e todo movimento, voluntário ou reflexo, é produzido pela contração dos músculos esqueléticos. O comportamento motor é a interação de muitas partes corporais, o que envolve o processamento da informação sensorial, integração e tomada de decisões pelos centros de controle neural, e a execução das respostas motoras apropriadas.

A informação sensorial é captada pelos receptores sensitivos e transmitida a centros apropriados no Sistema Nervoso Central (SNC), onde é interpretada e traduzida num programa motor apropriado. Em seguida, o programa motor é executado, músculos selecionados são engajados, e tem início o movimento. A execução é dirigida por processos de "feedback"(O'SULLIVAN, 1993).

$\mathrm{O}$ autor ainda relata que podem ser identificados níveis de hierarquia de comando do SNC. Em geral, os centros mais elevados, o córtex associativo, desenvolvem o plano ou estratégia para o movimento. Os centros médios, gânglios da base, cerebelo e córtex sensório-motor, elaboram o plano reunindo os movimentos e posturas necessários. Os centros mais inferiores, a medula espinhal, propiciam informações acerca do ambiente e desempenho e traduzem o plano em ações musculares específicas. Os movimentos são modificados pela atividade do reflexo de estiramento. Estes níveis de controle precisam ser percebidos como uma hierarquia flexível, e não rígida, com interações contínuas sustentando o movimento distribuído por todo o sistema.

Lesões no SNC interferem nos processos do controle motor. Fraqueza, lentidão, fadiga, rigidez, falta de coordenação e movimentos anormais são distúrbios comuns do sistema motor. Ocasionalmente, os sintomas refletem problemas fo- 
cais isolados, como fraqueza facial unilateral ou queda do pé, enquanto outros sintomas refletem problemas em funções complexas e integradas do sistema motor, como dificuldade em falar ou andar (COLLINS, 1997).

A avaliação da disfunção do controle motor é um processo que possui características variadas e peculiares buscando identificar áreas de deficiência na função periférica ou central. Baseia-se amplamente numa apreciação subjetiva da função, freqüentemente um difícil processo para o estudante inicial.

As chaves para a avaliação e a reavaliação bem-sucedidas são a observação cuidadosa e sistemática e o registro acurado dos resultados. Há exemplos de sistemas de pontuação e formulário de avaliação (O'SULLIVAN, 1993). Porém, para que a avaliação seja considerada adequada, é de fundamental importância o conhecimento, por parte do fisioterapeuta, das teorias que regem o funcionamento neurofisiológico do processo de controle motor.

\section{Desenvolvimento motor}

É definido como a progressão das mudanças, tanto quantitativas como qualitativas, que vão desde a não diferenciação ou o estado imaturo até um estado altamente organizado, especializado ou maturo (LOPES, 2001).

$\mathrm{O}$ desenvolvimento motor geralmente avança nas direções céfalo-caudal e próximo-distal. O controle da cabeça é conseguido antes do controle do tronco e dos membros inferiores. O controle dos ombros e do quadril emerge com o do tronco, antes do controle distal dos membros. As respostas simpáticas predominam no início do desenvolvimento, enquanto que a homeostasia e as respostas parassimpáticas controladas emergem mais tarde. Os padrões motores de dominância reflexa e em massa precedem a integração dos reflexos e o controle voluntário seletivo do movimento. O controle motor geral precede o desenvolvimento do controle motor fino. Seqüências adicionais envolvem:

1. Movimentos de flexão e extensão antes da rotação;

2. Movimentos isométricos (sustentar-se numa postura) antes do controle isotônico (movimentar-se numa postura);

3. Controle excêntrico (movimentar-se deixando uma postura) antes do controle concêntrico (movimentar-se para assumir uma postura);

4. Padrões de movimentos simétricos antes dos padrões de movimentos assimétricos;

5. Movimentos discretos antes de seqüências de movimentos contínuos; controle estático antes do controle dinâmico da postura. 
O tratamento baseado em acurada avaliação do nível de desenvolvimento do paciente e que modela as seqüências normais de desenvolvimento pode auxiliar o paciente na recuperação do controle com maior rapidez e sucesso. Por exemplo, um paciente gravemente incapacitado por lesão cefálica necessitará readquirir o controle da cabeça e do tronco antes que o uso funcional dos membros possa ser tentado. Portanto, é de fundamental importância ao terapeuta o conhecimento dos estágios do desenvolvimento motor normal para, assim, iniciar eficiente avaliação e posterior programa de tratamento (BÖHEN, 2001).

\section{Estágios do desenvolvimento}

Os modelos de controle motor, inicialmente descritos por Rood, e, mais tarde, elaborados por Stockmeyer, assimilam os processos evolutivos normais e propiciam estrutura clínica útil para avaliação e tratamento dos pacientes com deficiências no controle motor. Portanto, são importante base conceitual de referência a procedimentos e planos de tratamento utilizados pelo fisioterapeuta no seu diadia. Os estágios são: mobilidade, estabilidade, mobilidade controlada e habilidade, muito bem descritos por O'Sullivan (1993), e serão adaptados para este trabalho, acrescidos de complementações necessárias.

1- Mobilidade: é o estágio inicial do desenvolvimento motor e caracterizase pelo desenvolvimento da mobilidade funcional. Os movimentos de mobilidade têm base reflexa e executam função protetora ampla ao recém-nascido. Com o progresso do desenvolvimento, o controle passa do âmbito reflexo ao voluntário. Um dos requisitos básicos a este estágio é a capacidade de iniciar o movimento, o que exige a adequada ativação dos músculos. O segundo requisito é a capacidade de movimentar-se em toda a amplitude, isso demanda vigor adequado, amplitude de movimento e flexibilidade.

2- Estabilidade: é definida como a capacidade de manter uma posição constante, em relação à gravidade. Também é conhecida como equilíbrio estático, ou reações posturais estáticas.

Durante todo o primeiro ano de vida, o bebê aprende a controlar a postura em posições progressivamente mais verticais e sujeitas à sustentação do peso. Podem ser identificadas três importantes progressões alternativas, referentes ao desenvolvimento: do controle da cabeça; da capacidade de sentar-se; da capacidade de ficar em pé. Coletivamente, representam a emergência do controle postural estático num pré-requisito essencial ao posterior desenvolvimento do controle dinâmico dos movimentos.

O desenvolvimento do controle da estabilidade pode ser fracionado em duas fases: a manutenção tônica e a co-contração. A primeira é definida como a ativação 
dos músculos posturais em nível de encurtamento máximo. A segunda refere-se à contração simultânea de músculos, tanto agonistas como antagonistas; funciona a nível ótimo na sustentação do corpo em posturas em que há sustentação de peso.

3- Mobilidade controlada: é o terceiro estágio do desenvolvimento do controle motor e está envolvido com a capacidade de mudar de posição enquanto é mantido o controle postural. Rood (apud O' SULLIVAN, 1993) empregou a frase "mobilidade superposta à estabilidade" ou "trabalho pesado" com referência ao movimento dos segmentos proximais, enquanto os segmentos distais, de mãos, joelhos e ou pés, permanecem fixos. Assim, o desenvolvimento do controle postural progride ao longo de um contínuo, desde o controle estático até o controle dinâmico.

Um funcionamento motor habilidoso requer interação equilibrada entre o controle estático e o controle dinâmico. As atividades da mobilidade controlada incluem a transferência de peso para frente ou para trás, de um lado para o outro, ou qualquer combinação possível.

4 - Habilidade: é um movimento coordenado evidenciado pela função motora final discreta superposta à estabilidade proximal. A estabilidade dinâmica do tronco e das articulações proximais é mantida durante as atividades, o que permite a interação com o ambiente. Exemplos de atividades em nível de habilidades são: funções promotoras de mastigação, deglutição e fala; funções manuais de preensão e manipulação; locomoção ou deambulação.

Os movimentos dos membros durante este estágio diferem-se dos movimentos observados nos estágios anteriores por estarem regulados com sincronização espacial e temporal precisas. Fitts (apud O'SULLIVAN, 1993) definiu resposta hábil como a sequiência de atividades organizadas, direcionadas a certas metas e que, efetivamente, utiliza feedback para a produção de movimentos delicadamente coordenados.

Deve haver flexibilidade na análise do movimento normal e seu desenvolvimento seqüencial. Existem certos padrões de movimento que podem variar em características tonais, aspectos de seqüências específicas e a natureza seqüencial do desenvolvimento. Contudo, a variação de comportamentos aceitáveis tem limitações, e variações além dessas fronteiras são percebidas pela maioria das pessoas. 


\section{Procedimentos considerados na avaliação de desordens do con- trole motor}

A avaliação do controle motor, como qualquer outra avaliação neurológica, começa no primeiro contato com o paciente. É muito importante a observação indireta que leve em consideração outros componentes a influenciar direta ou indiretamente na condição do paciente, assim como no controle motor. Dessa forma, priorizamse os seguintes componentes numa avaliação do controle motor:

a) estado mental;

b) capacidade de comunicação: os problemas de recepção auditiva ou visual podem prejudicar significativamente o desempenho de uma avaliação fisioterápica;

c) prontidão ou estado central de alerta é importante na determinação do grau no qual um indivíduo é capaz de responder; freqüentemente, são empregadas mensurações do sistema nervoso autônomo (SNA) na determinação dos níveis de prontidão e no estabelecimento de valores da base para uma série de funções corporais;

d) função sensorial: é um componente crítico do controle motor porque propicia o feedback necessário usado na monitoração do desempenho; a isto denominamos de controle motor em alça fechada. Um exame sensorial em cada um dos sistemas empregados na monitoração do movimento, inclusive olhos, orelhas, aparelho vestibular, músculos, proprioceptores tendíneos e articulares, etc, é parte importante da avaliação do controle motor. Deve-se, também, incluir uma série de sequiências de movimentos rápidos, bem aprendidos. Muitas tarefas motoras são concretizadas por meio de combinação tanto dos processos em alça aberta, quanto em alça fechada, os quais devem ser avaliados.

e) função perceptiva: é definida como seleção, integração e interpretação dos estímulos sensoriais do corpo e do ambiente circunjacente. Devemos suspeitar de problemas perceptivos quando o paciente exibe grande dificuldade em concretizar uma tarefa, ainda que não possam ser detectadas causas específicas, como, por exemplo, espasticidade, fraqueza. Pacientes com lesões perceptivas também revelam dificuldades na execução de tarefas simples com independência e segurança na concretização de tarefas e na passagem de uma tarefa para outra; tendem a cometer repetidamente os mesmos erros e, com freqüência, exibem redução na capacidade de localizar visualmente, ou de identificar, objetos que pareçam necessários à concretização da tarefa; também apresentam dificuldade em acompanhar instruções simples, ainda que o nível de compreensão seja bom. Indivíduos 
perceptivamente prejudicados são impulsivos, intratáveis e frustrados e exibem baixa capacidade de planejamento. Pacientes que não atentam para um dos lados do corpo ou que negam a presença ou extensão da incapacidade também devem ficar sob suspeita de disfunção perceptiva.

\section{Função motora}

Esta função pode ser avaliada com base em vários parâmetros, entre eles, o tônus, os reflexos, as reações e os estágios do controle motor. A avaliação do tônus muscular busca identificar a tensão de repouso e a reatividade dos músculos ao alongamento passivo. O tônus é categorizado como hipertônico, aumentado e acima dos níveis normais em repouso, e hipotônico, reduzido e abaixo dos níveis normais em repouso.

Segundo O'Sullivan (1993), o tônus pode ser influenciado por diversos fatores, tais como: posição e interação dos reflexos tônicos; estresse e ansiedade; esforço ou movimento voluntário; medicamentos; estado do SNC. O terapeuta deve considerar o impacto de cada um desses fatores ao chegar à determinação do tônus. A avaliação do tônus exige repetidos exames porque são comuns flutuações em decorrência do estado constantemente mutuante da excitabilidade do SNC. A avaliação quantitativa pode ser considerada em três fases: observação inicial; avaliação do movimento passivo e dos reflexos miotáticos (de estiramento); controle motor voluntário.

\section{Controle do movimento voluntário}

O desenvolvimento ontogenético dos padrões de movimento progride desde padrões em massa ou totais de movimento até o controle seletivo de movimentos. Todavia, pode ser revertido no caso de lesão do SNC. Padrões em massa reemergem enquanto o controle seletivo dos movimentos se torna desordenado ou desaparece completamente. O termo sinergismo é frequientemente utilizado nessas circunstâncias, com referência aos padrões de movimentos estereotipados que emergem após a ocorrência de lesões cerebrais. Os sinergismos anormais são altamente previsíveis e restritos. Podem ser promovidos tanto por ação reflexa, como uma reação associada, quanto voluntariamente, como, por exemplo, nos casos de hemiplegia.

À medida que progride a recuperação do SNC, as sinergias tornam-se mais variáveis, podendo re-emergir apenas sob certas condições, como o estresse ou a fadiga. A diminuição da dominância das sinergias e a maior variação dos movi- 
mentos disponíveis tornam-se os marcos da recuperação seqüencial. Pacientes firmemente presos em padrões sinérgicos não podem isolar os movimentos individuais. Portanto, não são apropriados os procedimentos padronizados de testes musculares manuais, pois os movimentos não correspondem às ações musculares individuais esperadas.

\section{Conclusão}

A reabilitação efetiva deve levar em consideração o conhecimento atual sobre como o sistema nervoso participa do comportamento normal e também do anormal. O controle motor é um processo multifacetado que integra várias estruturas do sistema nervoso assim como outros componentes do organismo humano. Isso exige do estudante ou profissional profundo conhecimento e capacidade de integração das partes que lidam direta ou indiretamente na produção de um movimento. Outro fator importante é a capacidade de aplicação prática desses conhecimentos no dia-dia, no trabalho com os pacientes.

A avaliação de pacientes com disfunção do controle motor precisa ter como base a comparação com a função normal. O terapeuta precisa ser capaz de reconhecer, categorizar e hierarquizar apropriadamente os comportamentos motores para que se desenvolvam metas e estratégias terapêuticas efetivas. Os problemas individuais de cada paciente também exigem que o terapeuta reconheça uma série de fatores inter-relacionados, como: motivações, necessidades individuais, preocupações potenciais.

Da mesma forma, na avaliação do controle motor, devemos analisar outra série de fatores distintos, desde fatores periféricos da amplitude de movimento, força muscular até os mais centrais, como tônus, reflexos e padrões gerais de organização dentro do SNC. Não se pode deixar de levar em consideração a avaliação dos sistemas sensório-motores.

O processo de avaliação do controle motor é relacionado à capacidade de o terapeuta observar, analisar e categorizar acuradamente o comportamento. A determinação de fatores causais, responsáveis por padrões anormais de movimento, precisa basear-se em comparação de respostas esperadas ou normais com as anormais do paciente. Isso pode ser melhor concretizado por meio de abordagem sistemática e aprofundada. 


\section{Referências}

BEVILACQUA, Fernando et al. Fisiopatologia clínica. 5 ed. São Paulo: Atheneu, 1998.

BÖHME, Maria T. Silveira. Desenvolvimento motor. Disponível em: <http://www.cev.ucb.br/ qq/paulo/desmot.html> acesso em: 05 ago 2001.

COHEN, Helen. Neurociências para fisioterapeutas: Incluindo correlações clínicas. 2.ed. São Paulo: Manole, 2001.

COLLINS, Robert C. Neurologia. Rio de Janeiro: Guanabara Koogan S.A., 1997.

ENOKA, Roger M. Bases neuromecânicas da cinesiologia. 2 ed. São Paulo: Manole, 2000.

GARDINER, M. Dena. Manual de terapia por exercícios. São Paulo: Santos, 1995.

KOTTKE, Frederic J. \& LEHMANN, Justus F. Tratado de medicina física e reabilitação de Krusen. 4 ed. São Paulo: Manole, 1994.

LOPES, V. P. Desenvolvimento Motor. Disponível em: <http://www.ppb.pt/ vplopes/ DesMotor/Aulas/1-introducao/introducao-ficheiros/frame/htm $>$ acesso em: 06 set 2001.

MARQUES, Inara. A teoria dos estágios aplicada aos estudos do

desenvolvimento motor: uma revisão. Revista da Educação Física UEM. V.7, n. 11996.

O’SUULIVAN, Susan B. \& SCHIMITZ, Thomas J. Fisioterapia: avaliação e tratamento. 2. ed. São Paulo, 1993.

PORTO, Celmo Celeno. Exame clínico 3 ed. Rio de Janeiro: Guanabara Koogan S.A., 1996.

RASCH, Philip J. Cinesiologia e anatomia aplicada. 7 ed. Rio de Janeiro: Guanabara Koogan S.A., 1991.

ROWLAND, Lewis P. Merrit-Tratado de neurologia. 9 ed. Rio de Janeiro: Guanabara Koogan S.A., 1997.

SMITH, Laura K. et al. Cinesiologia clínica de Brunnstrom. 5 ed. São Paulo: Manole, 1997.

STOKES, Maria. Neurologia para fisioterapeutas (Cash). São Paulo: Premier, 2000.

UMPHRED, Darcy Ann. Fisioterapia neurológica. 2. ed. São Paulo: Manole, 1994. 